\title{
Pilar Pérez. Archivos del silencio. Estado, indígenas y violencia en Patagonia Central, 1878-1941. Buenos Aires: Prometeo, 2016, 460 páginas.
}

\author{
Laura Kropff ${ }^{1}$
}

$\mathrm{E}^{\mathrm{n}}$ n este libro, Pilar Pérez aborda la producción del espacio social en Patagonia a partir de su incorporación al Estado argentino y hasta principios de la década de 1940, con énfasis en los territorios nacionales de Río Negro y Chubut. Analiza al Estado desde una perspectiva que cuestiona la escisión liberal entre Estado y sociedad y privilegia la construcción de umbrales que intervienen en procesos de comunalización. Al respecto, examina al Estado desde -y en- sus márgenes, da cuenta de las representaciones y supuestos, las prácticas y dispositivos, y las (des)territorializaciones operantes. El libro consta de cinco extensos capítulos organizados por períodos en los que la estrategia argumentativa pasa por recomponer un proceso general y presentar casos particulares que abren nuevas preguntas. En ese sentido, emulando el segundo aspecto de la estrategia de la autora, más que presentar un resumen global de la publicación, me interesa destacar tópicos que promueven el debate. Entre las múltiples discusiones que propone, hay dos que tienen en común el hecho de que exceden el ámbito estrictamente académico para participar en un debate que se da a nivel de la opinión pública, los medios de comunicación, las organizaciones vinculadas a la lucha por los derechos de los pueblos originarios en Argentina y funcionarios del Estado a nivel nacional, provincial y municipal. Una de ellas tiene que ver con la interpretación de la conquista militar de la Patagonia como genocidio. La otra apunta al debate sobre la definición de las relaciones establecidas entre referentes indígenas y distintos organismos estatales en clave de estrategia o de cooptación.

La primera de las discusiones se presenta en torno a la tesis central del libro, que interpreta que el proceso de incorporación del territorio patagónico y su gente a la matriz Estado-Nación-Territorio es inaugurado por un genocidio que opera como evento estructurante de las relaciones sociales que se instauran. A partir de recuperar perspectivas trabajadas en el marco de la Red de Investigadores en Genocidio y Política Indígena de Argentina, de la que la autora participa, sostiene que el genocidio es un proceso que se divide en tres etapas

1 Consejo Nacional de Investigaciones Científicas y Técnicas/Universidad Nacional de Río Negro. Argentina. Correo electrónico: kropff@unrn.edu.ar 
que no son necesariamente consecutivas sino que deben entenderse, más bien, como operaciones que pueden solaparse. La primera de ellas es la manufacturación de un "otro interno" a través de la cristalización de identidades a las que se les asignan atributos culturales y físicos que se definen por oposición al modelo ideal del ciudadano de la nación. Este modelo se pone a circular provocando la exotización, el extrañamiento y la despolitización. Así, se traza y se naturaliza el límite entre la sociedad que hay que defender y aquello que la amenaza. El libro va demostrando cómo ese límite se va re-configurando en los distintos períodos que analiza. Repone cómo opera en cada contexto (re) produciendo la excepcionalidad normalizante de los indígenas como sujetos subalternos y sometidos y, a la vez, demarcando la movilidad de otros actores tales como los galeses, los gitanos, los migrantes europeos y sirio-libaneses. Ese límite también resguardará el lugar que ocuparán en la sociedad las estancias, las grandes casas comerciales, los almacenes de ramos generales y los mercachifles, entre otros actores.

La segunda etapa del genocidio es la violencia abierta para desarticular las relaciones sociales del grupo configurado como amenazante. En ese sentido, la autora argumenta en contra de la interpretación de la conquista militar de la Patagonia, denominada "Campaña del desierto", como si se hubiera tratado de una guerra. En su argumento demuestra que no había, en el contexto del siglo XIX, dos partes enfrentadas, sino una sociedad indígena heterogénea que no se percibía a sí misma como una totalidad, no tenía una organización política centralizada ni un ejército que actuara en su nombre. En función de ese argumento, Pérez se enfoca en lo que en los documentos oficiales aparece denominado como "la chusma". Se trata de familias y personas que no estaban identificadas con ningún cacique, que no conocían ni tenían clara la dimensión de las políticas desplegadas por el Estado, que tampoco estaban al tanto de las estrategias que desarrollaban los distintos caciques y que no tenían ninguna capacidad de negociación con el Estado. Sin embargo, sabían que el ejército perseguía, torturaba, deportaba y aterrorizaba, por lo que su opción fue escapar y esconderse. La autora deja instalada la pregunta por las alternativas que "la chusma" tenía cuando era atrapada por el ejército, a fin de discutir con una interpretación de estos hechos que es frecuente entre actores políticos que intervienen sobre la situación del Pueblo Mapuche en el presente: la calificación que distingue a los indígenas entre colaboradores y traidores. Al respecto, Pérez señala que "antes de hablar de traición y colaboración es necesario sopesar la dimensión de la violencia estatal sobre un conjunto poblacional amplio, heterogéneo, jerárquico y distribuido a lo largo de un territorio también múltiple" (p. 77). Desde su perspectiva, la noción de traición responde al 
supuesto de la existencia de un proyecto colectivo que no era tal y se funda en una dicotomía que responde a un umbral impuesto por el Estado. En esa línea, sostiene que la interpretación de lo ocurrido como guerra supone recuperar y reificar la perspectiva estatal para definir el proceso.

Finalmente, la tercera etapa del genocidio tiene que ver con la negación discursiva del proceso mismo. El foco aquí está puesto en la violencia simbólica ejercida sobre aquellos que fueron perseguidos y sobre la sociedad en general. Se trata de una forma de violencia que naturaliza las relaciones sociales instaladas por el genocidio al omitir o confundir los procesos que les dieron forma. La ausencia de un relato oficial sobre el genocidio generó un desafío metodológico para la investigación que sustenta el libro. Pérez tuvo que trabajar con lo que denomina un "archivo estallado", efecto de las técnicas legitimadoras de la consolidación estatal: el silencio y el secreto. Así, la autora diseñó una estrategia para rastrear lo que pudo ser dicho sobre un proceso sin relato oficial. Tuvo que trabajar con lo marginal dentro del archivo: documentos que no constituyen un fondo propio, series que pierden jerarquía en relación a otras, etc. El análisis de estos registros fue complementado con el abordaje de la prensa escrita y fuentes en mapuzugun [idioma mapuche] traducidas y recuperadas recientemente por otros investigadores, en un diálogo interdisciplinario entre historiadores y lingüistas. Además, el trabajo de campo etnográfico le permitió rescatar discursividades que definen los hechos desde otras lógicas.

La segunda de las discusiones a través de las que el libro dialoga con actores que no pertenecen a la academia es la que tiene que ver con la agencia indígena. El cuestionamiento inicial a la dicotomía entre colaboradores y traidores lleva a la autora a indagar en las estrategias que los indígenas se fueron dando para sobrevivir y, sobre todo, para no perder la tierra que les garantizaba tanto la subsistencia económica como la continuidad de su forma de vida. En ese sentido, hay dos experiencias que Pérez repone y que resultan provocadoras para poner en cuestión perspectivas que, en el presente, organizan la única posibilidad de acción política en la oposición indígenas/Estado.

La primera de esas experiencias es la de la Liga Patriótica Argentina, organización para-policial de ultra derecha que se instala en intendencias y gobernaciones de los territorios nacionales patagónicos alrededor de 1927, luego de la feroz represión a los huelguistas en Santa Cruz. El principal interés de los indígenas no era el mejoramiento de las condiciones laborales sino la ocupación de la tierra, por lo que no se plegaron masivamente a las huelgas promovidas por los trabajadores de las estancias. A partir de eso, la Liga establece una buena relación con los indígenas y les ofrece devolverles las tierras 
y construir escuelas a cambio de que se sumen a su gesta patriótica. Pérez da ejemplos de casos en los que la Liga actuó a favor de algunos indígenas en conflicto con grandes casas comerciales. En ese contexto, la autora da cuenta de que los miembros indígenas de la Liga Patriótica se reapropiaron de su discurso para tener legitimidad para reclamar la titulación de tierras. Así, al tiempo que pronunciaban discursos nacionalistas y repartían propaganda antisemita, trataban los asuntos de tierras.

La otra experiencia que el libro ofrece para el debate es la de la Asociación Nacional de Aborígenes (ANA). Se trata de una organización supra y trans-comunitaria con sede en Buenos Aires y base territorial en Neuquén, Río Negro y Chubut formalizada en 1920. La ANA se presenta como interlocutora con los gobiernos de los territorios a fin de visibilizar denuncias y organizar reclamos. Su estrategia incluyó la construcción de un discurso que se apropiaba de elementos del discurso hegemónico para tensionar las interpretaciones. Así, incorporaban a los indígenas dentro de la historia nacional argentina incluyendo los tropos de civilización y progreso en sus enunciaciones. Esto tuvo como efecto la desestabilización de los discursos sedimentados sobre lo indígena sin implicar una abierta oposición al Estado. Varios de los integrantes de la ANA fueron delegados en la Comisión Honoraria de Reducciones de Indios, órgano estatal creado en 1916 y abocado a temas de la Patagonia a partir de la década de 1930. Uno de sus logros más importantes fue la excepción del pago de pastaje para los indígenas en 1936, lo que contribuyó a que pudieran permanecer en la tierra. Los documentos dan cuenta de los recorridos de los delegados por distintos parajes para tramitar la excepción del pastaje y, a la vez, denunciar el avance de privados sobre tierras indígenas y otros abusos. Ambos casos, el de la Liga Patriótica y el de la ANA, pueden ser pensados en claves distintas: como fruto de la cooptación orientada a desarticular formas organizativas propias o como instancias de articulación para la interlocución con el Estado a fin de lograr injerencia en las decisiones y políticas implementadas para la población indígena. Al respecto, Pérez sostiene que "la cooptación debe ser antes analizada contemplando logros y fracasos en base a las opciones políticas de la agencia indígena" (p. 390).

Estas discusiones sobre la interpretación del proceso de incorporación y la agencia indígena, entre otras que el libro propone, hacen que tenga amplia circulación en el ámbito del activismo mapuche en Argentina y entre docentes de distintos niveles en la Patagonia. Al hacer el esfuerzo de desandar los secretos y los silencios oficiales, Archivos del Silencio constituye, en sí mismo, una apertura para hablar del asunto, una provocación para el debate y un gesto reparador. 